\title{
Discrimination and Exclusion on Grounds of Sexual and Gender Identity: Are LGBT People's Voices Heard at the Workplace?
}

\author{
Donatella Di Marco $^{1,2}$ (D), Helge Hoel $^{3}$ (D) and Duncan Lewis ${ }^{4}$ (D) \\ ${ }^{1}$ Universidad de Sevilla (Spain) \\ ${ }^{2}$ ISCTE-Instituto Universitário de Lisboa (Portugal) \\ ${ }^{3}$ The University of Manchester (UK) \\ ${ }^{4}$ Edith Cowan University (Australia)
}

\begin{abstract}
The review explores key issues associated with discrimination and hostility faced by Lesbian, Gay, Bisexual and Transgender (LGBT) people at work and organizational responses to it. Starting from a description of the main challenges facing LGBT workers' identity management, the review examines manifestations of negative attitudes towards gender and sexual minority groups, highlighting processes of subtle discrimination and exclusion. It presents and critiques dominant organizational responses to LGBT stigmatization, highlighting the need for holistic, intersectional approaches, and pointing out issues requiring further research.
\end{abstract}

Received 20 December 2020; Revised 29 January 2021; Accepted 12 February 2021

Keywords: discrimination, diversity management, inclusive organizations, LGBT workers, sexual and gender identity management

Social identities are relevant across all life domains because they help people to define themselves and to shape daily social interactions. Being authentic in the workplace is associated with positive outcomes in terms of job attitudes and well-being (Martinez et al., 2017). However, authenticity might be challenging for those groups historically stigmatized by society and who may have concealed identities, as is often the case for LGBT people (Croteau et al., 2008; Martinez et al., 2017). Although many countries reject discrimination based on sexuality and gender identity (McFadden \& Crowley-Henry, 2018), overt and subtle discrimination against non-heteronormative identities remains. As Hoel et al. (2014) reported, LGB workers are twice as likely to be victims of bullying and harassment than heterosexual colleagues. Moreover, almost 30\% of European transgender people perceive discrimination when looking for a job (European Union Agency for Fundamental Rights, 2013). At a time when some

\footnotetext{
Correspondence concerning this article should be addressed to Donatella Di Marco. Universidad de Sevilla. Departamento de Psicología Social. Calle Camilo José Cela, S/N. 41018 Sevilla (Spain).

E-mail: ddimarco@us.es. Phone: +34-954557345.

Conflicts of Interest: None.

Funding Statement: This research received no specific grant from any funding agency, commercial or not-for-profit sectors.
}

elements of society actively challenge the rights of LGBT people and other protected groups (Walker, 2020), organizations that enable people from diverse backgrounds to be themselves, to be included and feel safe at work is even more significant.

Starting with a brief review of research about sexual and gender identity management in workplaces, the article explores discriminatory and exclusionary processes experienced by LGBT workers. Given such a pretext, it critically evaluates the effectiveness of some mainstream organizational strategies aimed at tackling discrimination and progressing diversity and inclusion in the workplace. Finally, several issues requiring further research are identified.

\section{Managing Sexual and Gender Identity in the Workplace}

Perceived lack of visibility of sexual identities was the feature that conditioned many early studies in the field.

How to cite this article:

Di Marco, D., Hoel, H., \& Lewis, D. (2021). Discrimination and exclusion on grounds of sexual and gender identity: Are LGBT people's voices heard at the workplace? The Spanish Journal of Psychology, 24. e18. Doi:10.1017/SJP.2021.16 
In this assumption, sexual identity management was assumed and conceptualized as a process under the control of LGBT people themselves as to how, when and to whom one decides to make one's sexual orientation visible by disclosing it (Clair et al., 2005; Lidderdale et al., 2007; Ragins, 2008). Researchers' interest was initially focused on understanding which strategies people use to conceal (passing as heterosexual or covering information about their personal life) or disclose their sexual orientation (e.g., sharing information or cues to reveal it explicitly or implicitly); which individual characteristics (e.g., self-efficacy, expectations of outcomes, past discriminatory experiences) and organizational factors (LGBT affirmative policies, social support, etc.) might affect the strategy selection; and the consequences of such selection for people and organizations, in terms of well-being, job attitudes, turnover intentions, etc. (Clair et al., 2005; Lidderdale et al., 2007; Ragins, 2008; Wood, 1993).

However, increasingly it crystalized that disclosure is not a one-time choice or act (Button, 2004; Croteau et al., 2008; King et al., 2017), but an ongoing process implying decision making into revealing information about one's sexuality when one meets with new colleagues or new actors in the workspace. Moreover, the acceptance signals sent by interlocutors are decisive in determining degrees of disclosure by LGBT people (King et al., 2017).

According to recent studies (Di Marco et al., 2017; Einarsdóttir et al., 2016), the dynamic and interactional nature of such processes must be recognized, suggesting disclosure processes do not depend on LGBT individuals' wishes alone, but is affected by responses and interests of discloses or interaction partners. Informed by Boundary Theory Ashforth et al. (2000), Di Marco et al. (2017) suggest that depending on the response, non-heterosexual people might share information about their personal life at work (e.g., providing information about their partner), or, by contrast, where information given is ignored or rejected, this may prevent them being their authentic selves. Conversely, LGBT workers might wish to separate private lives from work life, deliberately omitting informational clues about their sexual orientation. However, this might not always be respected by colleagues, bothering them with questions or sometimes spreading rumors or 'outing' them within the organization (Di Marco et al., 2017). Such interactions also hinge on stereotyping, with colleague responses sometimes informed by stereotypical clues, which might act as a source of discrimination and exclusion whether clues are interpreted correctly or not (Di Marco et al., 2017; Einarsdóttir et al., 2016).

While research on identity management has traditionally focused on lesbian, gay and bisexual (LGB) workers, more recently scholars have started to address the dynamics of transgender people at work, whose disclosure experiences might be unique. Gender transition might or, might not involve physical changes or interventions; moreover, the degree of masculine and/or feminine characteristics transgender people adopt to express their gender identity can vary (Dieter \& Dentice, 2009). Bearing such variables in mind, if gender transition is carried out prior to employment, transgender workers might decide concealment, or "going stealth" (Beauregard et al., 2018, p. 10) to avoid negative colleague responses, or because they completely identify with their post-transition gender (Budge et al., 2010). However, desires to silence issues around their biological sex might be thwarted by co-workers asking questions or spreading rumors about colleagues whose gender expressions or physical attributes do not correspond to normative, binary masculine or feminine ones. Dynamics are different for transgender people who commence transitioning after entering the organization. In such cases, transgender people are often forced to negotiate or affirm their identity on a daily basis (Dietert \& Dentice, 2009), forcing departure from the organization when colleagues are unsupportive (Dietert \& Dentice, 2009).

\section{LGBT Workers' Stigmatization and Exclusion: From Overt to Covert Discrimination}

Disclosing sexual or gender identity might be a dilemma for LGBT workers. This is an historical stigmatization for not confirming normative expectations about affective relationships with gender expressions established by society, where homosexuality was considered a mental illness by the American Psychiatric Association until 1973, and where non-heterosexual acts and manifestations remain illegal in many jurisdictions (McPhail \& McNulty, 2015). Heteronormativity is the concept that reflects such norms, assuming that only two genders exist, based upon sex assigned at birth, and that they be expressed according to prevailing social norms of masculinity or femininity (Habarth, 2015). Heteronormativity also implies that only people of opposite sexes can hold romantic relationships, granting a hegemonic position to heterosexuality (Warner, 1991).

Socialization of heteronormative beliefs is considered to start at the early stages of child development and reinforced by social institutions representing breeding grounds for internalization of negative attitudes towards LGBT people as homophobia and transphobia. However, scholars have pointed out that the term "phobia" might undermine the comprehension of such phenomena, by considering the hostility against LGBT people as uncontrollable and irrational individual reactions (Herek \& McLemore, 2013). For this reason, the terms homo- and transphobia are increasingly replaced by new terms such as sexual and gender identity 
prejudice (Cramwinckel et al., 2018; Herek \& McLemore, 2013) and anti-homosexuality/antitransgenderism (Einarsdóttir et al., 2015; Hill \& Willoughby, 2005; Yep, 2003). The terms incorporate a broader range of, and motives for, hostile acts against LGBT people, going beyond the irrationality of the perceived phobia.

Social psychologists have tried to understand the mechanisms behind negative attitudes towards sexual minorities. In line with Social Identity Theory (Tajfel, 1978) and Self-Categorization Theory (Turner, 1982), people perceive and categorize themselves according to their group membership. Group belonging a source of self-esteem, allows people to define their identity, recognize appropriate behavioral and affective responses in certain contexts, setting the boundaries between one's own group (in-group) and others (outgroups) (Lewis et al., 2020). In order to protect selfesteem, people tend to minimize in-group members' negative or deviating behaviors and characteristics, instead emphasizing negative aspects of out-groups. In-group membership leads to rejection and stigmatization of those constituting threats to group identity. Therefore, LGBT people might be perceived as a threat by those defining and categorizing themselves and their own group by heteronormative norms and standards.

Although discrimination at work is outlawed by many countries, prejudice exists with organizations not immune to negative attitudes and discrimination. A distinction is often made between formal or institutional discrimination and interpersonal discrimination (Hebl et al., 2002; Jones et al., 2017). Whilst formal discrimination refers to prejudices and biased treatment of minorities, including LGBT people through organizational processes, policies and practices, such as recruitment, selection and career development (Hebl et al., 2002), interpersonal discrimination manifests during social interactions including verbal and non-verbal behaviors. Examples of the latter are derogatory language, or displaying discomfort during interactions with LGBT people (Hebl et al., 2002). Discrimination may occur openly or blatantly through behaviors that are easily recognizable as harming (e.g., direct verbal aggression). Bullying and harassment might form part of such blatant discrimination, with LGBT workers far more exposed than their heterosexual counterparts (see Hoel et al., 2018). But discrimination can also be subtle, through acts whose discriminatory intention is not clear to targets and observers. Selective incivility (Cortina, 2008), refers to rude or unkind behaviors, which might be attributed to reasons other than negative attitudes and bias. Moreover, the perpetrator's intention to harm has to be considered, whether it is conscious or unconscious. Concepts such as Microaggressions reflect implicit prejudicial and aggressive motives designed to injure feelings, whether intentional or not, and communicating hostile, derogatory slights and insults (Sue, 2010). Formal vs. interpersonal, overt vs. subtle, and conscious vs. unconscious represent the extreme ends of three continuums that are not mutually exclusive. Thus, a behavior might be interpersonal, subtle and conscious at the same time (Jones et al., 2017).

Studies about discrimination on grounds of sexual and gender identity within organizations show that one in five LGBT workers perceives themselves discriminated against (European Union Agency for Fundamental Rights, 2013). Notwithstanding, recent research appears to show increasing manifestations of subtle and interpersonal discriminatory acts (Corlett et al., 2019; Dietert \& Dentice, 2009; Di Marco et al., 2018; Einarsdóttir et al., 2015), also called modern discrimination (Cortina, 2008). Although many countries have made significant strides recognizing LGBT rights, negative attitudes might still persist at conscious and unconscious levels, and be expressed subtly to avoid social disapproval. A typical example would be using derogatory language and making uncivil or sexualized jokes; asking intrusive and inappropriate questions about private lives; and not using correct pronouns to refer to transgender colleagues. While many organizations condemn blatant aggressive acts and mistreatment of minority groups, including LGBT people, they often fail to call out subtle and ambiguous acts, seeing them as harmless, indirectly contributing to normalizing modern discrimination. Besides, whilst most studies examine LGBT workers' as a singular category, investigating the various groups separately shows that lesbians and bisexual women appear at greater risk than gay men (Hoel et al., 2014, 2018), indicating requirements for intersectional (Corrington et al., 2019) perspectives.

\section{Organizational Responses to Stigmatization}

Given LGBT workers' frequent exposure to discrimination in numerous forms, it is important to explore how organizations respond to rectify and challenge such experiences, enabling 'voice' and providing a sense of inclusion. Organizational motives to tackle discrimination range from upholding anti-discrimination laws (where they exist), to taking advantage of diversity (the business case for diversity), and pursuing moral and ethical values for creating a safe space for all (the moral case for diversity) (Bell et al., 2011). Many organizations develop and implement equal rights or diversity policies and practices to reduce bias, create awareness and challenge (subtle) discrimination, also strengthening the inclusion and visibility of minority groups. To achieve inclusion, diversity training is frequently deployed, although its effectiveness is 
questioned (Bezrukova et al., 2016; Kalinoski et al., 2013), because while such training may produce stable cognitive learning about improved interaction with minority groups, it rarely leads to changes in attitudes in the long-term (Bezrukova et al., 2016).

Recent meta-analysis showed that three types of organizational support moderate the negative effects of LGBT workers' stigmatization, namely formal policies and practices (e.g., top-management support for LGBT worker inclusion; providing benefits to employees' same-sex partners; and diversity training); a supportive climate (creating a safer and inclusive work environment); and relational support from colleagues and supervisors (Webster et al., 2018). According to the authors, a supportive climate with high levels of relational support contribute positively to LGBT workers' job satisfaction, commitment and disclosure; whilst at the same time reducing psychological strain and perceived discrimination. Although formal policies and practices also appear to work in the same direction, their impact is lower. Thus, formal statements supporting inclusive values and beliefs are not sufficient if lacking enactment on a daily basis (Clair et al., 2005).

Knowledge about social identity construction, categorization processes and diversity management have several implications for human resources practitioners. For instance, creating diverse teams with superordinate goals might help members to perceive themselves as part of a new group, where co-operation and interdependence are important to achieve common goals (Gaertner \& Dovidio, 2000; Lewis et al., 2020). The new collective group identity reduces risks of conflicts related to internal categorization processes tied to individual identities, allowing for expansion of the greater quantity of information available, improving group dynamics, meliorating decision-making processes and increasing creativity (van Knippenberg et al., 2004). Furthermore, in line with Social Contact Theory (Allport, 1954), the social contact of working to achieve shared goals can also disprove stereotypes and reduce prejudices (Pettigrew \& Tropp, 2006).

According to Bell et al. (2011), organizations need to provide LGBT workers with safe formal and informal voice mechanisms to increase visibility in the workplace and enable speaking up when unfair situations occur. Trade unions, where applicable, and LGBT networks can act as formal voice mechanisms, illuminating issues related to gender and sexual orientation minorities groups, and offering social support to LGBT workers. However, previous findings (McFadden \& CrowleyHenry, 2018) showed that some LGBT people do not access such participation channels believing their voice will be ignored. Moreover, speaking up might label them as troublemakers, increasing risks of mistreatment (McFadden \& Crowley-Henry, 2018). Therefore, organizations must foster formal voice channels by improving LGBT workers' voice self-efficacy and reducing acquiescence. In this respect, special attention must be given to transgender and bisexual employees who are included under the "LGBT diversity management" umbrella label but remain less visible and more stigmatized than lesbian and gay colleagues (Arena et al., 2017; McFadden \& Crowley-Henry, 2018). The scant presence of specific organizational policies and practices for transgender and bisexual workers exemplifies the lack of recognition of their specific needs (Arena et al., 2017; Beauregard et al., 2018).

Although formal voice mechanisms, including systems for complaints and mediation, are essential pieces of the participation system (Klaas et al., 2012), previous studies show that people often prefer to use informal voice channels, to address concerns to supervisors or line-managers (Olson-Buchanan \& Boswell, 2008). Perceiving their managers to be committed, trusted and supportive, who offer protection and set the tone of inclusion through role-modeling inclusive behavior, is key for improving access of LGBT workers to such channels (Bell et al., 2011; Di Marco, 2017). Moreover, the proximity of supervisors and line managers give them a privileged position to observe, recognize and stop subtle discriminatory acts, providing they are attuned to the signals of them. Therefore, selecting supervisors engaged with diversity issues or providing mandatory training to ensure they carry out roles effectively could make a difference towards the construction of inclusive and safe work environments.

To succeed, supervisors and managers need the reinforcement of senior management. In that sense, the adoption of formal policies and procedures, which establish clear pathways to embed equality and inclusion, might be through a decisive statement of organizational commitment. To practically address such issues, national and international organizations, including the International Labor Organization (ILO) and the International Standardization Organization (ISO) are currently advocating more holistic approaches. For instance, the British Standard on diversity and inclusion (BS76005) (Hoel \& McBride, 2017) provides a guideline to develop and implement policies and practices that value people and safeguard their dignity across the employment cycle. Such standards or codes of practice might assist in embedding diversity and inclusion within the organization, recognizing, valuing and giving voice to gender and sexual orientation minority identities.

Building effective organizational responses requires that the complexity of multiple challenges experienced by LGBT workers is acknowledged. Future research should explore how interpersonal dynamics at work may change when multiple stigmatized identities 
intersect (e.g., gender identity and race) (Corrington et al., 2019). To build comprehensive and inclusive diversity management programs, the paucity of research about the unique experience of bisexual and transgender workers (Arena et al., 2017; Beauregard et al., 2018) must be addressed. Additionally, researchers should identify organizational variables that empower LGBT workers and allies to speak up when recognizing subtle forms of discrimination.

In conclusion, recognizing and tackling discrimination on grounds of sexual orientation and gender identity entails multilevel actions and the commitment of several organizational actors including senior management. Making visible stigmatized identities, giving LGBT workers voice and raising awareness about LGBT issues are important steps to challenge belief systems and the many manifestations that maintain and reinforce heteronormativity within the organizational environment.

\section{References}

Allport, G. W. (1954). The nature of prejudice. Addison-Wesley. https: / / doi.org/10.2307/2573151

Arena, D. F., Jr., \& Jones, K. P. (2017). To “B” or not to “B”: Assessing the disclosure dilemma of bisexual individuals at work. Journal of Vocational Behavior, 103, 86-98. http:/ / doi.org/10.1016/j.jvb.2017.08.009

Ashforth, B. E., Kreiner, G. E., \& Fugate, M. (2000). All in a day's work: Boundaries and micro role transitions. The Academy of Management Review, 25, 472-491. https: / / doi.org/10.2307/259305

Beauregard, T. A., Arevshatian, L., Booth, J. E., \& Whittle, S. (2018). Listen carefully: Transgender voices in the workplace. The International Journal of Human Resource Management, 29, 857-884. https: / / doi.org/10.1080/09585192.2016.1234503

Bell, M. P., Özbilgin, M. F., Beauregard, T. A., \& Sürgevil, O. (2011). Voice, silence, and diversity in $21^{\text {st }}$ Century organizations: Strategies for inclusion of gay, lesbian, bisexual, and transgender employees. Human Resource Management, 50(1), 131-146. https:/ / doi.org/10.1002/ hrm.20401

Bezrukova, K., Spell, C. S., Perry, J. L., \& Jehn, K. A. (2016). A meta-analytical integration of over 40 years of research on diversity training evaluation. Psychological Bulletin, 142, 1227-1274. https: / / doi.org/10.1037/bul0000067

Budge, S. L., Tebbe, E. N., \& Howard, K. A. S. (2010). The work experiences of transgender individuals: Negotiating the transition and career decision-making processes. Journal of Counseling Psychology, 57(4), 377-393. https: / / doi.org/ 10.1037 / a0020472.

Button, S. B. (2004). Identity management strategies utilized by lesbian and gay employees: A quantitative explanation. Group E Organization Management, 29, 470-494. https:/ / doi.org/10.1177/1059601103257417

Clair, J. A., Beatty, J. E., \& MacLean, T. L. (2005). Out of sight but not out of mind: Managing invisible social identities in the workplace. Academy of Management Review, 30, 78-95. http:/ / doi.org/10.5465/amr.2005.15281431
Corlett, S., Di Marco, D., \& Arenas, A. (2019). 'Coming out' across cultures: Examining the experiences of Ecuadorian and Spanish LGB employees. Current Psychology. https:/ / doi.org/10.1007/s12144-019-00463-y

Cortina, L. M. (2008). Unseen injustice: Incivility as modern discrimination in organizations. Academy of Management Review33, 55-75. https:/ / doi.org/10.5465/ amr.2008.27745097

Corrington, A., Nittrouer, C. L., Trump-Steele, R. C. E., \& Hebl, M. (2019). Letting him B: A study on the intersection of gender and sexual orientation in the workplace. Journal of Vocational Behavior, 113, 129-142. https:/ / doi.org/10.1016/ j.jvb.2018.10.005

Cramwinckel, F. M., Scheepers, D. T., \& van der Toorn, J. (2018). Interventions to reduce blatant and subtle sexual orientation- and gender identity prejudice (SOGIP): Current knowledge and future directions. Social Issues and Policy Review, 12, 183-217. https: / / doi.org/10.1111/sipr.12044

Croteau, J. M., Anderson, M. Z., \& VanderWal, B. L. (2008). Models of workplace sexual identity disclosure and management: Reviewing and extending concepts. Group E Organization Management, 33, 532-565. https: / / doi.org /10.1177/1059601108321828

Dietert, M., \& Dentice, D. (2009). Gender identity issues and workplace discrimination: The transgender experience. Journal of Workplace Rights, 14, 121-140. https: / / doi.org/ 10.2190/wr.14.1.g

Di Marco, D. (2017). Unlocking closet at organizations. In A. Arenas, D. Di Marco, L. Munduate, \& M. Euwema (Eds.), Shaping inclusive workplaces through social dialogue. Industrial relations \& conflict management (pp. 187-200). Springer. http: / /doi.org/10.1007/978-3-319-66393-7_12

Di Marco, D., Hoel, H., Arenas, A., \& Munduate, L. (2018). Workplace incivility as modern sexual prejudice. Journal of Interpersonal Violence, 33, 1978-2004. https: / / doi.org/10.1177/0886260515621083

Di Marco, D., Munduate, L., Arenas, A., \& Hoel, H. (2017). ¿Quién queda en el armario? La experiencia de los colectivos de personas lesbianas y gais en el trabajo [Who is left in the wardrobe? The experience of lesbian and gay groups at work]. Ediciones Pirámide.

Einarsdóttir, A., Hoel, H., \& Lewis, D. (2015). It's nothing personal': Anti-homosexuality in the British workplace. Sociology, 49, 1183-1199. https: / / doi.org/10.1177/ 0038038515582160.

Einarsdóttir, A., Hoel, H., \& Lewis, D. (2016). Fitting the bill: (Dis)embodied disclosure of sexual identities in the workplace. Work, Employment and Society, 30, 489-505. https:/ / doi.org/10.1177/0950017014568136.

European Union Agency for Fundamental Right. (2013). European Union lesbian, gay, bisexual and transgender survey: Results at a glance. Publications Office of the European Union. https:/ / fra.europa.eu/en/publication/2013/eu-lgbtsurvey-european-union-lesbian-gay-bisexual-andtransgender-survey-results.

Gaertner, S. L., \& Dovidio, J. F. (2000). Reducing intergroup bias: The common ingroup identity model. Psychology Press.

Habarth, J. M. (2015). Development of the heteronormative attitudes and beliefs scale. Psychology \& Sexuality, 6(2), 166-188. https:/ / doi.org/10.1080/19419899.2013.876444. 
Hebl, M. R., Foster, J. B., Mannix, L. M., \& Dovidio, J. F. (2002). Formal and inter- personal discrimination: A field study of bias toward homosexual applicants.

Personality and Social Psychology Bulletin, 28, 815-825. https://doi.org/10.1177/0146167202289010.

Herek, G. M., \& McLemore, K. A. (2013). Sexual prejudice. Annual Review of Psychology, 64, 309-333. https:/ / doi.org/ 10.1146/annurev-psych-113011-143826.

Hill, D. B., \& Willoughby, B. L. B. (2005). The development and validation of the Genderism and Transphobia Scale. Sex Roles, 53, 531-544. https:/ / doi.org/10.1007/s11199-0057140-x.

Hoel, H., Lewis, D., \& Einarsdóttir, A. (2014). The ups and downs of LGBs' workplace experiences. Manchester Business School.

Hoel, H., Lewis D., \& Einarsdóttir A. (2018). Sexual orientation and workplace bullying. In P. D'Cruz, E. Noronha, C. Caponecchia, J. Escartín, D. Salin, \& M. Tuckey (Eds.), Dignity and inclusion at work. Handbooks of workplace bullying, emotional abuse and harassment (pp. 1-29). Springer. https:// doi.org/10.1007/978-981-10-5338-2_13-1.

Hoel, H., \& McBride, A. (2017). 'Getting in', 'staying in' and 'moving on': Using standards to achieve diversity and inclusion. In A. Arenas, D. Di Marco, L. Munduate, \& M. C. Euwema (Eds.), Shaping inclusive workplaces through social dialogue. Industrial relations \& conflict management (pp. 33-51). Springer. https: / / doi.org/10.1007/978-3-319-66393-7_3.

Jones, K. P., Arena, D. F., Nittrouer, C. L., Alonso, N. M., \& Lindsey, A. P. (2017). Subtle discrimination in the workplace: A vicious cycle. Industrial and Organizational Psychology, 10(1), 51-76. https://doi.org/10.1017/iop.2016.91.

Kalinoski, Z. T., Steele-Johnson, D., Peyton, E. J., Leas, K. A., Steinke, J., \& Bowling, N. A. (2013). A meta-analytic evaluation of diversity training outcomes. Journal of Organizational Behavior, 34, 1076-1104. https: / / doi.org/ 10.1002/job.1839.

Klaas, B. S., Olson-Buchanan, J. B., \& Ward, A.-K. (2012). The determinants of alternative forms of workplace voice. Journal of Management, 38(1), 314-345. https:/ / doi.org/10.1177/ 0149206311423823.

King, E. B., Mohr, J. J., Peddie, C. I., Jones, K. P., \& Kendra, M. (2017). Predictors of identity management: An exploratory experience-sampling study of lesbian, gay, and bisexual workers. Journal of Management, 43, 476-502. https: / / doi.org/10.1177/0149206314539350.

Lewis, D., Glambek, M., \& Hoel, H. (2020). The role of discrimination in bullying. In S. Einarsen, H. Hoel, D. Zapf, \& C. Cooper (Eds.), 'Bullying and harassment in the workplace: Developments in theory, research, and practice ( $3^{\text {rd }} \mathrm{Ed}$.). CRC Press, Taylor and Francis Group.

Lidderdale, M. A., Croteau, J. M., Anderson, M. Z., TovarMurray, D., \& Davis, J. M. (2007). Building LGB vocational psychology: A theoretical model of workplace sexual identity management. In K. J. Bieschke, R. M. Perez, \& K. A. DeBord (Eds.), Handbook of counseling and psychotherapy with lesbian, gay, and bisexual clients ( $2^{\text {nd }}$ Ed., pp. 245-270). American Psychological Association. https:/ / doi.org/ 10.1037/11482-010.
Martinez, L. R., Sawyer, K. B., Thoroughgood, C. N., Ruggs, E. N., \& Smith, N. A. (2017). The importance of being "me": The relation between authentic identity expression and transgender employees' work-related attitudes and experiences. Journal of Applied Psychology, 102, 215-226. https:/ / doi.org/10.1037/apl0000168.

McFadden, C., \& Crowley-Henry, M. (2018). 'My People': The potential of LGBT employee networks in reducing stigmatization and providing voice. The International Journal of Human Resource Management, 29, 1056-1081. https:/ / doi.org/10.1080/09585192.2017.1335339.

McPhail, R., \& McNulty, Y. (2015). “Oh, the places you won't go as an LGBT expat!" A study of HRM's duty of care to lesbian, gay, bisexual and transgender expatriates in dangerous locations. European Journal of International Management9(6), 737-765. https:/ / doi.org/10.1504/ EJIM.2015.072227.

Olson-Buchanan, J. B., \& Boswell, W. R. (2008). An integrative model of experiencing and responding to mistreatment at work. The Academy of Management Review, 33, 76-96. http:/ / doi.org/10.5465/amr.2008.27745325.

Pettigrew, T. F., \& Tropp, L. R. (2006). A meta-analytic test of intergroup contact theory. Journal of Personality and Social Psychology, 90, 751-783. https: / / doi.org/10.1037/00223514.90.5.751.

Ragins, B. R. (2008). Disclosure disconnects: Antecedents and consequences of disclosing invisible stigmas across life domains. Academy of Management Review, 33, 194-215. http:/ / doi.org/10.5465/amr.2008.27752724.

Sue, D. W. (2010). Microaggressions and marginality Manifestation, dynamics and impact. John Wiley and Sons.

Tajfel, H. (1978). The achievement of inter-group differentiation. In H. Tajfel (Ed.), Differentiation between social groups (pp. 77-100). Academic Press.

Turner, J. C. (1982). Towards a cognitive redefinition of the social group. In H. Tajfel (Ed.), Social identity and intergroup relations (pp. 15-40). Cambridge University Press.

van Knippenberg, D., De Dreu, C. K. W., \& Homan A. C. (2004). Work group diversity and group performance: An integrative model and research agenda. Journal of Applied Psychology, 89, 1008-1022. https:/ / doi.org/10.1037/00219010.89.6.1008.

Walker, S. (2020, November 11). Hungarian government mounts new assault on LGBT rights. The Guardian. https:/ / www.theguardian.com/world/2020/nov/11/hungariangovernment-mounts-new-assault-on-lgbt-rights.

Warner, M. (1991). Introduction: Fear of a queer planet. Social Text, 29, 3-17.

Webster, J. R., Adams, G. A., Maranto, C. L., Sawyer, K., \& Thoroughgood, C. (2018). Workplace contextual supports for LGBT employees: A review, meta-analysis, and agenda for future research. Human Resource Management, 57, 193-210. https://doi.org/10.1002/hrm.21873.

Woods, J. D. (1993). The corporate closet: The professional lives of gay men in America. Free Press.

Yep, G. A. (2003). The violence of heteronormativity in communication studies. Journal of Homosexuality, 45(2), 11-59. https://doi.org/10.1300/J082v45n02_02. 